UDC 376.1

DOI: $10.23951 / 2782-2575-2021-1-47-55$

\title{
PSYCHOLOGICAL AND PEDAGOGICAL SUPPORT FOR AN EXCEPTIONAL CHILD IN AN INCLUSIVE CLASS: COMPARISON OF WESTERN AND RUSSIAN REFLECTION*
}

\author{
Yu.V. Melnik \\ Moscow State University of Psychology and Education, Moscow, Russian Federation
}

\begin{abstract}
A comparative analysis of theoretical and conceptual ideas in the organization and further implementation of psychological and pedagogical support for an exceptional student in an inclusive educational process is carried out. Psychological and pedagogical methods for emphatic comfort initiation for each child in an inclusive educational environment are highlighted. Practical examples of such techniques are creating social success situations for an exceptional person in an inclusive group, introducing elements of creativity to solve possible issues. The principles of psychological and pedagogical support that contribute to the success of an exceptional child in an inclusive class are the following: resistance, cooperation between all participants, reliance on the potential of the student's personality, and others. Pedagogical modifications that optimize the process of inclusive learning are the following: change of motives for inclusive education, consolidation of positive behavioral forms of communication in an inclusive group, and other modifications. The types of adaptability formed due to effective psychological and pedagogical support of an exceptional child in an inclusive environment are considered: epistemological, perceptual, sociocommunicative, and semiotic adaptation.
\end{abstract}

Keywords: psychological and pedagogical support, inclusive education, exceptional child, exceptionality, educational psychologist.

An inclusive educational process is a fusion of various entities that determine the success of the psychological well-being and the academic effectiveness of an exceptional child in an inclusive group. In this study, exceptionality means the presence of explicit (external) or implicit (internal) individual characteristics, which cause specific antagonisms in the area of complete cultural, socio-psychological, and pedagogical adaptation to the requirements of the general educational system. This also directly affects the formation of a non-trivial image of self-concepts with a modified set of social-role repertoire.

Such ontogenetic deviations of biosocial order can include disability, giftedness, poverty, ethnic, religious, cultural, and linguistic minorities. In these conditions, the implementation of techniques for relevant psychological and pedagogical support for an exceptional child is an essential factor in eliminating internal frustration and increasing his or her epistemological potential for adequate interiorization of the cognitive basis and the development of an acceptable behavior model in the society.

The formation and practical intervention of psychological and pedagogical support strategies in an inclusive classroom always act as a polythematic semantic category that includes a complex of variable dispositions. Describing the actual content of the accompanying route for an exceptional child in psychological and pedagogical aspects, T. Smith and M. Peterson point to the

* Original Russian language version of the article: Melnik Yu.V. Psychologo-pedagogichesko soprovozhdenie netipichnogo rebenka v inklyuzivnom klasse: komparatsiya zapadnoy i rossiyskoy refleksii [Psychological and Pedagogical Support for an Atypical Child in An Inclusive Class: Comparison of Western and Russian Reflection]. Nauchno-pedagogicheskoye obozreniye - Pedagogical Review. 2018;2 (20):95-105. DOI: $10.23951 / 2307-6127-2018-2-95-105$ 
presence of a priority expressive-emphatic teleology (a target base aimed at solving variable psycho-emotional problems) of an educational psychologist in his or her interaction with all participants in the inclusive educational process. In the course of establishing a dialog with an exceptional child, the critical goal of psychological support is to construct a basis of a positive connotative (positively colored) background of expression, which makes it possible for each child to exteriorize (reveal) inherent learning abilities to the maximum extent and develop skills of effective communication with peers, as well as productive cultural socialization $[1,2]$.

The author assesses this point of view as productive since the primary transformation of the emphatic background of inclusion is one of the leading and priority components in developing a strategy for satisfying the personal, communicative, interpersonal, cultural, and educational needs of each child. In the case of the presence of certain pronounced deviations from a given imperative, the creation of a positive psychological background of interaction between all subjects of inclusive education plays a binary role in constructing the state of individual satisfaction of a special student with his or her position in the children's group, and the intensification of mnemonic (operational-mental) functions to acquire the required amount of material. At the same time, the author believes it's necessary to highlight specific psychological and pedagogical methods of initiating emphatic comfort for each child in an inclusive educational environment, which contribute to the work of an educational psychologist both with a group and individuals. These include:

1. The creation of a positive self-image on a personal level. In this case, psychological and pedagogical support comes from the conscious development of a range of environmental conditions conducive to the formation and further development of high-quality techniques for individual social perception. An important aspect here is the formation and disclosure of potential reserves for positive self-perception by implementing training to create a relevant and holistic self-image. In this context, the primary semantic role is played by the psychologist's possession of basic knowledge about the basics of children's compensatory skills, cultural identity in childhood, and the practical skills of introducing techniques for compensating specific restrictive forces arising from biological, social, personal or communicative imbalances.

2. Perception of pluralism in an inclusive environment through the prism of a positive cognitive-behavioral approach. The formation of psychological and pedagogical support for an exceptional student, in this case, comes from the construction of a stable motivational basis among all subjects of inclusion to a positive perception of any forms of "non-standardness" as immanent (integral) elements of the anthropological continuum existence in general and of a specific educational community in particular. At the same time, cognitive-behavioral strategies among all children in the inclusive class include gradual development of a stable relationship between mental formations. This is related to the normalization of various forms of otherness and the consolidation of the created perceptual images in the system of socially approved norms of behavior when communicating with their exceptional peer. Building such a balance makes it possible to optimize the psychological attitude in the children's group to implement the tactics of accepting an exceptional peer in the academic and social components of the educational process.

3. Search and gradual implementation of creative solution elements to the various levels of contradictions emerging in the educational process. Psychological and pedagogical work is defined here as a triggering mechanism for the initiation of possible non-trivial manifestations of existence (meaningful life activity) in the subject-activity, philosophical, personality-oriented, and moral-moral approaches. Finding a set of non-standard solutions to eliminate the actual and potential problems in the inclusive class should be built considering the pronounced psychological correlation between the thought processes of excitability and inhibition in each subject 
of inclusion. Adequate and timely focus on these mental functions allows you to select a range of tasks for each child, which entirely takes into account the individual temporal characteristics and learning abilities.

4. Development on a conscious level of situations where a special student is successful in academic and social life. Creation of conditions where the exteriorization of the latent reserves of each subject of activity makes it possible to consolidate the feeling of individual assertiveness at the mental, social, existential, sensory levels under the action of various life circumstances. This factor ensures the formation of a sense of affiliation to society in general and the inclusive class particularly.

5. Introduction of a variable therapeutic spectrum into the academic and social life of an inclusive class. The active development and further testing of various types of therapies for a special student balance the internal life resources and adequately distribute available reserves for solving current educational and social tasks in operational, tactical, and strategic plans. A prerequisite for the successful implementation of this disposition is the psychological and pedagogical consideration of the specific ontogenetic stage of the child's development within the framework of age and social gradation and the ability to include all other subjects of inclusion in the developed therapeutic work practices. In this case, the harmonization of the general connotative background of the inclusive class can be successfully carried out with the disclosure of positive emphatic foundations existing in the perceptual background of all participants of the inclusive education and upbringing.

6. Developing skills for positive catharsis in an inclusive classroom and teaching cathartic techniques to support each subject of inclusion. Having the basics for strong empathy to an exceptional child and providing him or her with the required types of assistance make it possible to build relevant and productive communication in the following systems: "exceptional student typical peer" and "exceptional student - significant adult." The key and fundamental point here is the teacher psychologist's demonstration of the practice of parity catharsis, in which a flexible balance is achieved between the principles of individual autonomy in the educational process and children's collectivism while providing compensation for disturbed or distorted vital functions.

7. Provision of facilitation and mediation techniques after a complete psychological and pedagogical history analysis of exceptional child data. The creation of a portrait of a special student with the formation of a single image of his or her psychological characteristics and pedagogical capabilities within the framework of personal ontogenesis always comes from a combinatorial understanding of the children's functions performed in various activities. In this aspect, the educational psychologist plays the role of a coordinator and facilitator in forming the required database and its subsequent updating. An essential point is a professional ability to preserve facilitation and mediation skills in a prolonged mode when analyzing individual points of growth and development of an exceptional student at each age point. Such practices ensure the unity of ideas among professionals of various thematic areas about the problems existing in an exceptional child and the reserves for eliminating the arising antinomies.

8. Taking into account the cumulative effect while an exceptional child acquires academic knowledge and social skills. Within the framework of the indicated dispositive method of psychological and pedagogical support, it is necessary to consider the observance of the continuity elements when achieving certain stages of personal growth. In this regard, the functional role of the educational psychologist consists in the resistant training of the necessary skills for the interiorization of educational material and social communication among all subjects of inclusion. At the same time, cumulation should be considered as a stable basis for the further progressive 
development of exceptional individuals and ensure the stability of their intrapersonal intentions to demonstrate positive forms of communication with others and to master the required educational standards.

The Russian paradigm of psychological and pedagogical support of exceptional children in an inclusive educational process also recognizes the importance of emphasizing the interpersonal relationship in an inclusive classroom and the simultaneous harmonization of the emotional background during the educational process. Revealing the essential characteristics of emotional interactions between any participants of the educational process, L. S. Vygotsky and S. L. Rubinstein define the structure of any personality as a multi-component model. Within this model, a uniform functional distribution carries biological, social factors, and personalityanthropomorphic factors - its layer of character, made up of individual characteristics of any subject of communication, which arise due to its uniqueness and positive distinction from other individuals in the social field of interactivity. A proper combination of the designated components allows forming a personality with a set of necessary skills for the comprehensive implementation of communicative intentions [3-5].

In the author's opinion, the presented point of view has unconditional modulation rationality since it includes the factorial triad of the formation of socially oriented foundations for any personality. In the presence of some exceptional features, these components also retain their semantic and teleological characteristics.

At the same time, for their relevant functioning and correlation, it is necessary to comply with a number of principles of psychological and pedagogical support that contribute to the success of an exceptional child in an inclusive class and his or her comfortable psychosocial well-being among typical peers. These principles include:

- resistance of the psychological and pedagogical influence;

- thematic focus on the spheres of the exceptional child existence who, due to a combination of various reasons, is exposed to social deprivations;

- holistic and temporal adequacy of psychological and pedagogical support;

- taking into account the primary interests and needs of the exceptional student at a priority level;

- reliance on the existing internal potential of the student's personality;

- progressive dialectics of individual growth and development of special children;

- intensification with subsequent enrichment of mnemonic functions in exceptional students;

- observance of the cooperation techniques between all subjects of the inclusive educational process;

- gradual development of skills to the required types of activity;

- identification and constant reliance on the leading signal systems for the perception of information in an exceptional student with the accumulation of an epistemological base and social experience of communication;

- maintaining a balance when working as a teacher-psychologist with a child with special educational needs;

- development of motivational and volitional personal qualities of an exceptional student through the demonstration of their behavioral patterns, as well as behavioral patterns in an inclusive educational environment;

- formation of a stable basis for the mnemonic functions of an exceptional child through conducting special psychology and defectology classes;

- a combination of individual and group forms of work with an exceptional student; 
- active introduction of elements of interpersonal interactivity to an exceptional student when performing social communication functions;

- stable consolidation of the acquired skills of psychological and pedagogical communication both in school and outside it;

- teaching the skills of psychological self-defense against possible frustration in a group;

- the constant emphasis on the destruction of discretion in the system "operational-tacticalstrategic objectives" transitioned to a meaningful unity of these components.

So, the comparison of the reflective vision of the psychological and pedagogical support for an exceptional student in a situation of inclusion in the Western and Russian understanding indicates some distinctive differences in the qualitative content of the existing emotional background in an inclusive classroom. The Russian paradigm has a greater degree of detailing of this vision. Within its framework, the layer of any individual personality is distinguished, which occupies the middle position between the environmental and organic determinants of any person's formation in society. Western pedagogical thought is more generalized in its content and in the category of anthropo-social factors has internal elements of the personal culture itself, formed under the influence of the inner intentions and motives of the individual himself.

Among the general characteristics of Western and Russian reflection of the emphatic mode of an inclusive class in a psychological and pedagogical context, the unity of awareness of environmental and biological determinants stands out as uniform factors of any student growth and development, regardless of the manifestation of his or her individual distinctive features.

In direct correlation with the communicative and perceptual aspects of psychological and pedagogical assistance to an exceptional child in an inclusive class, there are modification ideas about behavioral class management as the basis for developing behavioral strategies that are acceptable in a particular society. This semantic relationship is due to the ratio of generalized and detailed aspects of inclusion at the psychological level. With an adequate organization of communication and social perception with an exceptional student, a holistic transformation of the general behavioral patterns of all subjects of inclusion takes place. This includes the formation of variable psychological patterns associated with achieving a balance between objectification and subjectivity of self-perception, as well as the individual well-being of special children in a peer group. Reflecting the essential content of behavioral management S. Vauchn, R. M. Garzhulo, and V. Jones point to the pivotal role of the educational psychologist in an inclusive classroom as the main initiator and, at the same time, stabilizer of the introduced changes. At the same time, various modifications should always be accompanied by a set of imitation practices that allow all children in an inclusive class to form on a personal level a sense of assertiveness, anthropophilia, as well as develop psychological readiness for the necessary techniques to identify themselves with a significant environment. The consistent implementation of imitation teaching methods determines the successful formation and development of all cognitive and communicative functions of a person, which in general determines the success of special children in solving a set of academic, intrapersonal, interpersonal, and social tasks [6-8].

The presented position, according to the authors, has a pronounced positivity. Since in this case, there is a semantic understanding of the general psychological and pedagogical foundations of inclusive educational activity, and the very social and psychological well-being of special children is assessed as an immanent component of behavioral management, which allows all children to equally develop their creative inclinations and characteristics for productive interaction with a child with special educational needs. Along with this, it is necessary to highlight specific targeted changes on a teacher on the psychological level, ensuring holistic inclusion and full 
exteriorization of the exceptional student's abilities to study and communicate within the created field of contact. Such pedagogical changes include:

1. Teleological change of motives of inclusive education. It is defined as a conscious distance from the traditional understanding of educational activities focusing on the priority of the academization of the educational process. In this case, the functional role of the teacherpsychologist is to take into account and focus on the social development priorities of each subject in the educational process. It is essential to follow the postulate of dialectics in the field of psychological and pedagogical growth of a child, emphasizing the achieved learning outcomes in the context of social adaptability, integrativity, and flexibility of all children in an inclusive class.

2. Consolidation of positive behavioral forms through psychological techniques to reinforce a positive pattern of action. Professional competence consists of demonstrating such positive behavioral forms by personal example and eliminating possible characterological traits of character accentuation in individuals with exceptionality. Such a restructuring determines the overall success of psychological and pedagogical support for non-standard children.

3. Changing the traditional focus of thinking in all participants of inclusion in the framework of the normalization theory. The defining value of psychological and pedagogical support lies in this situation in the movement from the principle of hypertrophied mainstreaming (excessive striving to endow the individual with typical features) and the transition to the paradigm of nontriviality pluralistic sense. Constant consideration and reliance on non-standard properties and qualities of an individual student make it possible to semantically transform the understanding of personal characteristics from the point of view of their potential to form an inclusive class as a microsocial continuum, which harmonizes the general tactics of psychological and pedagogical support of exceptional children at school.

4. Leveling socio-psychological expectations from all children involved in the educational process. In this aspect, psychological and pedagogical support is defined as the starting line for building a single equality trajectory and equal expectations from all children, regardless of their differences. The professional activity allows you to eliminate the manifestation of otherness and create a standard line of dialectical growth of the child in the academic and social senses.

5. Timeliness of psychological and pedagogical correction of possible negative manifestations concerning an exceptional student. The introduction and consistency of corrective work methods into the inclusive educational activities determine the opportunity to optimize the sociopsychological atmosphere in an inclusive group and create the effect of self-perception of this community as a we-community. In this case, the role of the educational psychologist is to reveal the implicit dispositions (internal characteristics) of the psychological and pedagogical state of each participant in the team with the maximum possible development of his or her sense of assertiveness and distance from stigmatized relational "glasses."

6. Conscientiousness of equal distribution of rights and obligations in all areas of inclusive educational activities. In this case, the pedagogical process's psychological support consists of the rejection of a central focus on different social and legal dispositions. This approach determines the overall success of the psychological adaptation of each individual to the existing environment. It allows to timely achieve the effect of pluralistic thinking for any person, regardless of the mental state, exercises a range of their powers on a certain issue of existence in a uniform and equal way.

7. Increasing the level of individual susceptibility of special children. This task can be achieved through the teacher-psychologist's conscious inclusion of social praxis elements, making it possible to develop skills for interiorizing the material in a social context. The indicated 
situation contributes to an increase in all participants' flexibility and eliminates possible psychological destruction (environmental or biological).

8. Testing the ability to achieve positive autonomy for an exceptional student in an inclusive classroom. The noted modification guarantees a comprehensive disclosure of the special childrens' individuality and the feeling of their self-integrity in various social situations. Such psychological formations improve adaptive skills with specific characteristics and create an essential background for their full inclusion in an inclusive class with existing academic and social realities.

The Russian understanding of behavioral management in the psychological and pedagogical aspect emphasizes the adaptive and communicative properties of the individual.

At the same time, behavioral management is considered as a teleological toolkit for the implementation of the individual's comprehensive abilities to achieve the necessary adaptation indicators, which directly and indirectly improve communication skills with society and provides prerequisites for the comprehensive realization of "sociophilia." Reflecting this point of view, A. A. Nalchajyan, E. P. Ilyin, and Yu. V. Khotinets define the personal field of an individual as a set of diverse motives, the correlation between which leads to the effective implementation of the law of conjugate development of mental phenomena. As a result of the personality motivational base transformation, the spectrum of its actual and potential adaptability at various levels increases and, as a result, reciprocal communication is carried out between all participants with an expressed cathartic and affiliation basis, as well as the development of coping strategies to overcome complex issues [9-11].

The communicative-adaptive interpretation of behavioral management at the psychological and pedagogical level indicated by these researchers has binary significance in certain types of exceptionality. Implementation of an inclusive educational paradigm closely correlates with the law of coupled development since changes in the socio-psychological well-being and the level of readiness for inclusion among typical students entail a decrease in the manifestations of residual forms of autostigmatization in an exceptional student. Such interdependence and complementarity reflectively affect the quality of the integral communicative background in an inclusive classroom and create the necessary prerequisites intensifying all children's academic and social abilities. At the same time, it is expedient to single out specific types of adaptability, formed by positive behavioral management in an inclusive class, with a short description of the basic semantic content of a specific adaptability type as a component of the productive social identity formation. In this regard, the following types of adaptability can be distinguished:

1. Epistemological adaptability. An exceptional child in an inclusive class, in many cases, experiences variable discomfort of various origins. In this regard, the formation of individual adaptation at the cognitive level is the primary link for establishing a social dialogue system with peers and a teacher. Such a situation indirectly entails the enrichment of the communicative field with the introduction of theoretical and practice-oriented elements into it, which leads to the development of a positive socio-cultural identity of a particular person with peers.

2. Perceptual adaptability. It is based on the development of a stable base for the inclusive education perception, not in the context of philanthropy, but within the framework of the legalization of the child with special educational needs rights to master the aggregate basis of knowledge. The formation of pronounced adaptation at the perceptual level in all participants of inclusive education optimizes and facilitates the general process of psychological and pedagogical support in the classroom, which expands the possibilities for a positive interpretation of any forms of nontriviality and creates a sound basis for consolidating academic and social results of the activity. 
3. Social and communicative adaptation. It contains the key determinants for the successful development of any child in a group. The role of the educational psychologist is defined here through the implementation of his or her competent responsibility for the social microclimate in the children's group and the elimination of distorted forms of communication with the absence of parity positions in the dialogue. Timely and adequate psychological support serves as a necessary basis for all participants in inclusive education to initiate equality, non-discrimination, and the interactivity of the educational process.

4. Semiotic adaptation. It has a pronounced implicit meaning and involves the vision of the latent attributes of inclusive learning. All participants' ability to recognize signal-sign elements in educational discourse creates a holistic background for eliminating possible hidden psychological, pedagogical, or social antagonisms.

Comparative analysis of the Western and Russian behavioral management foundations in an inclusive classroom in a psychological and pedagogical context reveals the presence of significant convergence. This convergence combines the semantic understanding of the behavioral patterns management as a leading factor in the formation of a favorable socio-psychological background of inclusive education and upbringing, where academic and social achievements of special children are equally taken into account, and inclusion itself has the character of parity, holism, and resistance.

Among the distinguishing features stands out a different focus on individual dispositions of behavioral management. Within the framework of the Western paradigm, a competency-based approach is taken into account, focused primarily on the imitation of relevant behavioral forms by an educational psychologist so that the exceptional student could master them. In the Russian interpretation, there is a pronounced centering on the adaptive and communicative aspects of each participant's personality of educational activity.

These forms contain both positive and negative practice-oriented aspects. On the one hand, in this case, a significant degree of individualization of the learning process is achieved, which consequently increases the psychological readiness for learning of all individuals and eliminates possible social antagonisms. On the other hand, insufficient consideration of the organizational and competence aspects of educational activity reduces the general ordering of mental functions of any individual at the academic and social levels. This forms the preconditions for specific manifestations of the exclusion of exceptional children from the educational continuum.

Thus, the reflection of an exceptional child's psychological and pedagogical support in an inclusive class in the Western and Russian understanding demonstrates the presence of divergence components in various detailed aspects, among which theoretical-psychological, communicative, status-role, and functional-activity orientations stand out most clearly. At the same time, there is a convergence of reflexive paradigms in the teleological basis of psychological and pedagogical support. This support includes maximum possible inclusion of a the child with special educational needs in the spectrum of academic and environmental realities with the development of his or her psychological readiness for inclusive learning and the development of stable "sociophilia" towards the subjects of his or her immediate environment, and also the formation of adaptability to possible stressful situations that arise during the inclusive educational process.

\section{References}

1. Smith T.E. Teaching students with special needs in inclusive settings. 4th ed. Boston, MA, Pearson Education, Inc., 2008. $465 \mathrm{p}$.

2. Peterson M.J. Inclusive teaching: The journey towards effective schools for all learners. 2th ed. Boston, MA, Pearson Education, Inc., 2010. 507 p. 
3. Vygotskiy L.S. Pedagogicheskaya psikhologiya [Pedagogical psychology]. Moscow, Pedagogika-Press Publ., 1996. 536 p. (in Russian).

4. Rubinshteyn S.L. Osnovy obshchey psikhologii [Bases of general psychology]. St. Petersburg, Piter Publ., 2002. 720 p. (in Russian).

5. Abul'khanova K.A. Metodologicheskiy printsip sub"yekta: issledovaniye zhiznennogo puti lichnosti [Methodological principle of subject: research of personality's life journey]. Psikhologicheskiy zhurnal Psychological Journal, 2014, no. 2, pp. 5-18 (in Russian).

6. Vaughn S., Bos C.S. Strategies for teaching students with learning and behavior problems. 8th ed. Upper Saddle River, NJ, Pearson Education, Inc., 2012. 450 p.

7. Gargiulo R.M., Metcalf D. Teaching in today's inclusive classrooms: a universal design for learning approach. Belmont, CA, Wadsworth Cengage Learning, 2013. 504 p.

8. Jones V., Jones L. Comprehensive classroom management: creating communities of support and solving problems. Boston, Pearson Education, Inc., 2007. 480 p.

9. Nalchadzhyan A.A. Psikhologicheskaya adaptatsiya: mekhanizmy i strategii [Psychological adaptation: mechanisms and strategies]. Moscow, Eksmo Publ., 2010. 368 p. (in Russian).

10. Il'in E.P. Psikhologiya obshcheniya i mezhlichnostnykh otnosheniy [Psychology of communication and interpersonal relationships]. St. Petersburg, Piter Publ., 2012. 576 p. (in Russian).

11. Khotinets Yu.V., Korobeynikova A.Ya. Psikhologicheskiye mekhanizmy produktivnogo koping-povedeniya $\mathrm{v}$ problemnykh kommunikativnykh situatsiyakh [Psychological mechanisms of productive coping behavior in problematic communicative situations]. Psikhologicheskiy zhurnal-Psychological Journal, 2016, vol. 37, no. 4, pp. 59-73 (in Russian).

Yuliya V. Melnik, Moscow State University of Psychology and Education (ul. Sretenka, 29, Moscow, Russian Federation, 127051).

E-mail: melnik_stav@mail.ru 